\title{
A argumentação no ensino de ciências no âmbito escolar: o antagonismo entre o que consta no Currículo Oficial do Estado de São Paulo e, as afirmações dos discentes
}

Agnaldo Ronie Pezarini ${ }^{1}$

Maria Delourdes Maciel ${ }^{2}$

\section{Resumo}

Este artigo tem o objetivo de discutir o antagonismo observado entre o que consta no Currículo Oficial do Estado de São Paulo e as afirmações de discentes. Os dados obtidos para esta discussão se deram por meio questionário aos participantes, alunos do 9o ano dos Anos Finais do Ensino Fundamental e da 3a série do Ensino Médio e, à posteriori os analisamos por meio da categorização. Tendo ratificado a existência da habilidade argumentativa no referido currículo promovemos uma discussão em torno de duas categorias. As discussões realizadas, nos permitem afirmar que, o sucesso do desenvolvimento da habilidade argumentativa está intrínseco ao papel do professor que deve ser ativo no processo de construção e que o antagonismo está relacionado à carência na formação específica e as dificuldades em romper com sua prática de ensino de modo a modificá-la.

Palavras-chave: Argumentação no Ensino de Ciências; Currículo do Estado de São Paulo; Ciências da Natureza; Competências e Habilidades; Antagonismo e Resistência.

The argumentation in science education in the school ambit: the antagonism between that which consists in official curriculum of São Paulo state and the affirmation of the students

\section{Abstract}

This article aims to discuss the antagonism observed between what is in the Official Curriculum of the State of São Paulo and the statements of students. The data obtained for this discussion were given by means of a questionnaire to the participants, students from the 9th grade of the Final Years of Elementary School and the 3rd grade of High School and, afterwards, we analyzed them by means of categorization. Having ratified the existence of the argumentative ability in the mentioned curriculum we promoted a discussion around two categories. The discussions held allow us to state that the successful development of argumentative ability is intrinsic to the role of the teacher who must be active in the construction process and that the antagonism is related to the lack of specific training and the difficulties in breaking with their teaching practice in order to modify it.

Keywords: Argumentation in the Teaching of Sciences; The Curriculum of São Paulo State; Natural Science; Competence and Abilities; Antagonism and Resistance.

\section{Introdução}

A argumentação no Ensino de Ciências (EC) no que se refere a construção e a formação científica deveria ser vista como uma ação comum e corriqueira nas práticas pedagógicas escolares, no entanto, ao que parece, esta é uma afirmação que está em descompasso com a

\footnotetext{
${ }^{1}$ Universidade Cruzeiro do Sul, São Paulo, rpezarini@gmail.com

2 Universidade Cruzeiro do Sul, São Paulo, delourdes.maciel@gmail.com
} 
realidade da formação discente. Promover a construção do conhecimento científico é o viés das disciplinas da subárea da Ciências da Natureza, mas como lograr este objetivo? Consideramos que, a promoção do conhecimento científico não é uma ação que se resume em acumulação de fatos, conceitos, informações e dados, mas sim, é um processo de construção gradativa que deve ter como um de seus elementos o discurso e, neste sentido, cabe a argumentação, ou seja, desenvolver a competência e a habilidade da argumentação é um ato essencial para a aprendizagem científica.

A constatação de que há um, descompasso entre a ação argumentação no EC com o propósito da formação científica e a realidade praticada nas escolas foi obtida com a aplicação de um questionário com discentes do Ensino Fundamental e Médio de uma escola Estadual do Estado de São Paulo, onde os participantes revelam dados de extrema importância para validar a triste configuração do ensino de ciências e de disciplinas da área.

Diante do exposto, o objetivo deste artigo é discutir o antagonismo observado entre o que consta no Currículo Oficial do Estado de São Paulo e as afirmações de discentes referentes às existências e práticas pedagógicas frequentes em sala de aula para o desenvolvimento da argumentação no EC para à posteriori relacionar a existência e/ou ausência desta competência com os dados obtidos com a aplicação do questionário de coleta de dados.

A análise do referido currículo e o confronto dos dados obtidos irá caracterizar a realidade da aprendizagem científica no contexto da escola estadual do Estado de São Paulo e, a partir desta caracterização será possível indicar caminhos, subsídios e planos de ação que possam ressignificar o processo de aprendizagem científica.

De forma a dar subsídios as discussões futuras, cabe a apresentação e contextualização dos temas centrais deste estudo, ou seja, as premissas e as especificidades do Currículo Oficial do Estado de São Paulo e da Argumentação no EC.

Enfim, a prerrogativa de construção da aprendizagem científica pelo viés argumentativo é certamente uma ação que promove a melhora significativa no pensar dos estudantes, logo, acreditamos que, o ensino da argumentação deve ser de forma contínua e explícita pois diante destas ações se é possível a aquisição do conhecimento científico. 


\section{O Currículo do Estado de São Paulo para as Ciências da Natureza}

Com vista a promover a unificação curricular das escolas sob sua jurisprudência, o Governo do Estado de São Paulo através da Secretaria do Estado da Educação implantou em 2007 um currículo único, com a justificativa de que todas as unidades escolares pertencentes a esta rede dialogariam da mesma maneira e, ainda segundo Castro (2008), promover uma política educacional compreendida por uma ação integrada e articulada, com vistas ao objetivo organizar o sistema educacional de São Paulo.

À época, a implementação deste currículo foi objeto de discussões, uma vez que a iniciativa de maior impacto foi a sua implementação. Em 2008 ocorre a publicação deste Currículo que continha os princípios curriculares, sínteses das áreas de conhecimento, concepção da disciplina e os conteúdos distribuídos por série de escolarização e bimestre. Com isso houve a elaboração e a distribuição dos chamados Caderno do Professor, no mesmo ano, e do Caderno do Aluno, em 2009.

Uma das justificativas para a implementação do Currículo Oficial é a sua relação com o Sistema de Avaliação de Rendimento Escolar do Estado de São Paulo (SARESP) uma vez que, apresenta objetivos que estão em consonância com esta relação conforme o documento da Secretaria do Estado da Educação do Estado de São Paulo, que cita

\footnotetext{
Verificar o desempenho dos alunos da educação básica pra fornecer informações a todas as instâncias do sistema de ensino que subsidiem a capacitação dos recursos humanos do magistério; a reorientação da proposta pedagógica das escolas, de modo a aprimorá-la; a viabilização da articulação dos resultados da avaliação com o planejamento escolar, capacitação e o estabelecimento de metas para o projeto de cada escola (SECRETARIA DO ESTADO DA EDUCAÇÃO, 1996, p.7).
}

A referida relação é enaltecida pela fala da então assessora da Secretaria de Educação, Maria Inês Fini conforme cita Sousa e Arcas (2010):

fizemos todo um esforço para preparar a toda nossa rede, desde 2007, um currículo que definisse as bases mínimas e comuns a que todas as crianças e jovens de São Paulo tenham o direito de ter acesso para construir os seus conhecimentos. Anunciamos esse currículo como a primeira etapa e que se

Periódico Horizontes - USF - Itatiba, SP - Brasil - e020016 
seguiria o processo de avaliação, agora aprimorado, e que deveria estar estruturado a serviço deste currículo (SOUSA; ARCAS, 2010, p.186-187).

Vale ressaltar que os Cadernos, tanto do aluno quanto do professor, foram criados por profissionais ligados a Universidades tendo como mediador deste processo a Fundação Vanzolini, logo a responsabilidade e participação da Secretaria do Estado da Educação, neste caso, se limitou à indicação das diretrizes de formatação e dos princípios pedagógicos, em especial no que tange ao fato de que o currículo deveria ser voltado para o desenvolvimento de competências e habilidades.

Ratifica a afirmação de que o objetivo do Currículo Oficial do Estado de São Paulo está no desenvolvimento de competências e habilidades, Santos e Frenedozo (2017), ao dizerem que:

\begin{abstract}
O documento intitulado Documento Básico apresenta a linha balizadora do ensino e aprendizagem da rede oficial de ensino da SEE/SP e afirma que, doravante, esse ensino deverá ser praticado com vista ao desenvolvimento de competências e habilidades indispensáveis ao exercício da cidadania, mundo do trabalho e continuidade dos estudos em nível superior. Para isso, esse documento declara que esse ensino deve ser pautado pelos seguintes princípios: a- Uma escola que também aprende; b- $O$ currículo como espaço de cultura; c- As competências como referência; $d$ - Prioridade para a competência da leitura e da escrita; e- Articulação das competências para aprender e; fArticulação com o mundo do trabalho (SANTOS; FRENEDOZO, 2017, p.3).
\end{abstract}

Tendo exposto que o viés do Currículo Oficial do Estado de São Paulo é o desenvolvimento de competências e habilidades cabe especificar qual a sua essência e, para tanto recorremos ao próprio documento em questão, São Paulo (2012), que descreve a sua composição e o seu conteúdo

O Currículo Oficial se completa com um conjunto de documentos dirigidos especialmente aos professores e aos alunos: os Cadernos do Professor e do Aluno, organizados por disciplina/ série(ano)/bimestre. Neles, são apresentadas Situações de Aprendizagem para orientar o trabalho do professor no ensino dos conteúdos disciplinares específicos e a aprendizagem dos alunos. Esses conteúdos, habilidades e competências são organizados por série/ano e acompanhados de orientações para a gestão da aprendizagem em sala de aula e para a avaliação e a recuperação. Oferecem também sugestões de métodos e estratégias de trabalho para as aulas, experimentações, projetos coletivos, atividades extraclasse e estudos interdisciplinares (SÃO PAULO, 2012, p.8). 
Ao estabelecermos relação entre as especificidades deste Currículo Oficial com a do EC vislumbramos que, para com esta área de ensino, o objetivo está em privilegiar o desenvolvimento da cultura científica e a promoção de competências e de habilidades mais gerais ou mais específicas. Com relação as tais competências descritas neste documento, apontamos aquilo que consta no mesmo que dá ênfase a tais fatos, como conta em São Paulo (2012) quando descreve:

Entre as competências mais centrais em todas as áreas e, portanto, também nas ciências, estão as que qualificam para comunicar, expressar, representar, argumentar, ou seja, as competências do domínio das muitas formas de linguagem, incluídas as de leitura e escrita, essenciais para o convívio contemporâneo. Nas ciências, essas competências são manifestas ou compostas por meio de inúmeras habilidades, algumas mais específicas dessa área, outras comuns às demais, como ler e expressar-se com textos, cifras, ícones, gráficos, tabelas e fórmulas; converter uma linguagem em outra; registrar medidas e observações; descrever situações; planejar e realizar entrevistas; sistematizar dados; elaborar relatórios; participar de reuniões; elaborar e defender argumentações; trabalhar em grupo (SÃO PAULO, 2012, p.28, grifo nosso).

Apontamos em destaque na citação retirada do Currículo Oficial do Estado de São Paulo (SÃO PAULO, 2012) dois termos de salutar importância para as discussões deste artigo, os mesmos são: argumentar e argumentações. Enfatizamos que o objetivo deste artigo é de analisar o currículo em questão em busca de evidencias da presença ou ausência de ações, meios, objetivos e desenvolvimento de ações que estejam voltadas a argumentação para buscar resposta aos resultados obtidos com a aplicação de um questionário a discentes de uma escola da rede de ensino a qual pertence o currículo em processo de análise. Vale ainda apontar que o Currículo de Ciências está estruturado em torno de quatro eixos temáticos: Vida e ambiente, Ciência e tecnologia, Ser humano e saúde e Terra e Universo, que se repetem ao longo dos quatro anos do ensino fundamental anos finais, de 60 ano ao 90 ano. Por sua vez, cada um desses eixos temáticos estrutura-se em subtemas, de acordo com a série, conforme descrito no quadro 1. 
Quadro 1 - Eixos temáticos e subtemas do Currículo de Ciências

\begin{tabular}{|l|l|}
\hline \multicolumn{1}{|c|}{ Eixos temáticos } & \multicolumn{1}{c|}{ Subtemas } \\
\hline Vida e ambiente & $\begin{array}{l}\text { Meio ambiente (5a série/6o ano); Os seres vivos (6a série/7o ano); Manutenção de } \\
\text { espécies (7a série/8o ano); Relações com o ambiente (8a série/9o ano) }\end{array}$ \\
\hline Ciência e tecnologia & $\begin{array}{l}\text { Materiais do cotidiano e sistema produtivo (5a série/6o ano); A tecnologia e os seres } \\
\text { vivos (6a série/7o ano); Energia no cotidiano e no sistema produtivo (7a série/80 ano); } \\
\text { Constituição, interações e transformações dos materiais (8a série/9o ano); Usos } \\
\text { tecnológicos das radiações (8a série/9o ano) }\end{array}$ \\
\hline Ser humano e saúde & $\begin{array}{l}\text { Qualidade de vida: saúde individual, coletiva e ambiental (5a série/6o ano); Saúde: um } \\
\text { direito da cidadania (6a série/7o ano); Manutenção do organismo (7a série/80 ano); } \\
\text { Córdenação das funções orgânicas (8a série/9o ano); Preservando o organismo (8a }\end{array}$ \\
\hline \multirow{2}{*}{ serra e Universo } & $\begin{array}{l}\text { Planeta Terra: características e estrutura (5a série/6o ano); Olhando para o céu (6a } \\
\text { série/7o ano); Planeta Terra e sua vizinhança cósmica (7a série/8o ano) }\end{array}$ \\
\hline
\end{tabular}

Fonte: SÃO PAULO, 2012, p.34

Tendo exposto os eixos temáticos para o ensino de ciências conforme descreve o currículo do Estado de São Paulo, salientamos que, logo em seguida o referido documento descreve o quadro de conteúdos e habilidades para cada ano de ciclo do Ensino Fundamental Anos Finais (6ㅇ ano 9 ano) estando o mesmo subdividido para os quatro bimestres do ano letivo.

De modo bem peculiar analisaremos nestes quadros de conteúdos e habilidades dos EC e do Biologia, em específico nas orientações de habilidades a serem construídas àquelas que fazem referência ao foco de discussão deste artigo, ou seja, a argumentação.

\section{A argumentação no Ensino de Ciências}

O contexto escolar e as ações desenvolvidas neste ambiente estão intrínsecos a ação do discurso argumentativo (COSTA, 2008), logo, acreditamos que, o âmbito educacional deve se voltar para o desenvolvimento da competência argumentativa nos discentes em processo de formação. Diante desta afirmação, que se faz urgente e necessária a construção da habilidade argumentativa cabe de imediato que conceituemos dois termos essenciais deste processo, 0 
argumento e a argumentação, bem como apresentemos meios pelos quais a referida construção possa ser desenvolvida.

Quando tratamos da temática argumentação no ensino de ciências há equívocos de conceito, uma vez que os leigos se referem aos termos argumento e argumentação como sinônimos e, para tanto, recorremos a Costa (2008) que explora a diferenciação à luz de Sibel Erduran, Van Eemeren e Jiménez Aleixandre, autores que conceituam e distinguem os referidos termos.

Segundo Sibel Erduran (2006), o termo argumento refere-se à essência das teorias, dados, justificações e backing (conhecimento básico) que contribuem para o conteúdo do argumento. Argumentação refere-se ao processo de associar aqueles componentes; desempenha um papel central na construção de explicações, modelos e teorias. De acordo com van Eemeren e outros (1987), a argumentação é uma atividade social, intelectual, verbal e não verbal, utilizada para justificar ou refutar uma opinião; engloba um conjunto específico de declarações dirigido para obter a aprovação de um ponto de vista particular por um ou mais interlocutores. Para M. P. Jiménez Aleixandre (2006), argumentação é a capacidade de relacionar dados e conclusões, e avaliar enunciados teóricos à luz dos dados empíricos ou provenientes de outras fontes (COSTA, 2008, p.2).

A citação acima ratifica que há uma distinção entre o conceito do argumento e da argumentação, fato que, precisa ser evidenciado junto aos discentes em processo de formação, uma vez que, a aquisição dos mesmos conduz à prática por ser um modo de compreender, explicar e criticar e, acima de tudo evitar confusões quanto ao conceito.

Sabendo que, a aquisição da habilidade argumentativa se faz por meio de ações específicas, cabe a indagação: Qual(is) são as estratégias e/ou metodologias de ensino capazes de concretizar a construção da habilidade argumentativa? Esta é uma indagação que precisa estar entre os objetivos de ação do docente das disciplinas da subárea da Ciência da Natureza, uma vez que, desenvolver esta habilidade nos discentes, sejam eles de qualquer ciclo de ensino são uma ação que requer de antemão o rompimento de paradigmas e o desprendimento das mesmices para com o processo de aprendizagem.

Monteiro e Teixeira (2004) sinalizam em seu trabalho que o desenvolvimento da competência e da habilidade argumentativa tem estreita relação com a ação do docente em prol da construção da mesma, é preciso que o professor em suas ações conduza a construção do argumento 
Os resultados deste trabalho também possibilitaram perceber a capacidade que as crianças demonstram ter para construir argumentos. [...] os alunos se mostraram capazes de descrever suas ações e construir justificativas plausíveis para elas. Entretanto, como era de se esperar, essa competência dos alunos se mostrou dependente da postura discursiva do professor. [...] Conduzir a aula, saber preparar as atividades, tendo em mente o que vai ensinar, como vai ensinar e porque vai ensinar, são atitudes de que o professor não pode se eximir. Estimular a observação, dar contornos mais precisos a ideias que começam a ser construídas pelos alunos, sugerir uma melhor organização das atividades em sala de aula, estimular a participação de todos, garantir a livre manifestação de pensamentos, evitando polarizações de opiniões, são algumas das muitas atitudes do professor que devem estar asseguradas para que os alunos possam construir argumentos segundo as características sociais da cultura científica (MONTEIRO; TEIXEIRA, 2004, p.261-262).

Identificamos neste sentido que, a argumentação no ensino de ciências requer a efetiva participação do docente para que se possa lograr o objetivo proposto e, para além disto evidenciamos que há por traz deste processo uma outra ação que é específica, sendo ela a de maior valia dentro do processo de aprendizagem da disciplina de Ciências.

Estamos nos referindo a Alfabetização Científica (AC) que por sua vez está em consonância a com a indagação feita anteriormente e, neste sentido é preciso enaltecer e enfatizar o processo de $A C$ e as premissas por trás deste processo, mas sempre pelo viés da formação cientifica global para que o aluno tenha consciência e percepção de seu mundo e, não apenas a formação de futuros cientistas.

O processo de alfabetização científica requer que as aulas de Ciências sejam realizadas por um viés de discussões e, neste sentido, evidenciados a presença do discurso e, neste sentido ratificamos a necessidade da promoção do desenvolvimento da argumentação nas aulas de ciências. Logo, há uma intrínseca relação entre a argumentação e o processo de alfabetização científica, lembrando que, é pela AC que o aluno em processo de formação tem contato com as especificidades do pensar científico. Corrobora com esta diversidade e peculiaridades do processo de alfabetização Sasseron e Carvalho (2008), quando discutem sobre as especificidades deste processo.

Em nossa visão, para o início do processo de Alfabetização Científica é importante que os alunos travem contato e conhecimento de habilidades 
legitimamente associadas ao trabalho do cientista. As habilidades a que nos referimos também devem cooperar em nossas observações e análise de episódios em sala de aula para elucidar o modo como um aluno reage e age quando se depara com algum problema durante as discussões. Acreditamos existir alguns indicadores de que estas habilidades estão sendo trabalhadas e desenvolvidas entre os alunos, ou seja, alguns indicadores da Alfabetização Científica, que devem ser encontrados durante as aulas de Ciências e que podem nos fornece evidências se o processo de Alfabetização Científica está se desenvolvendo entre estes alunos (SASSERON; CARVALHO, 2008, p.337-338).

De forma a ratificar esta relação entre a argumentação e a Alfabetização científica apontamos o trabalho de Sasseron e Carvalho (2011) que recorreram ao Padrão de Toulmin para a construção da argumentação e, foi por meio desta ação que evidenciaram a presença de indicadores da Alfabetização científica nos alunos.

Ao constatar a presença e o aparecimento dos indicadores da AC durante a sequência dos turnos analisados, temos clara a existência de um ciclo argumentativo envolvendo a divulgação da construção do entendimento de um conceito ou de um tema pelos alunos. Entendemos este ciclo argumentativo como a forma por meio do qual as argumentações se desencadeiam e a maneira como as relações entre diferentes dados e variáveis são estabelecidas [...]. Uma característica interessante das argumentações merece ser destacada e comentada aqui: temos percebido uma relação bastante intensa e profícua entre o aparecimento e uso dos indicadores da $A C$ e o padrão de argumentação de Toulmin (2006) (SASSERON; CARVALHO, 2011, p.111).

O Padrão de argumentação de Toulmin é o de maior evidência nas pesquisas sobre esta temática. Sendo o Padrão de Toulmin o de maior evidência e aplicabilidade nas pesquisas, cabe elucidar e caracterizar esta ferramenta. O referido padrão apresenta, no que se refere à sua identidade e elementos constituintes, algumas especificidades conforme nos apontadas Scarpa e Trivelato:

$O$ passo que autoriza o estabelecimento de uma afirmação $C$ a partir dos dados D é chamado de garantia (W). A garantia é a informação a partir da qual argumentamos. No entanto, a garantia somente será válida em virtude de certos fatos, observações, experimentos, leis e conhecimentos mediante os quais foram estabelecidas. As garantias têm avais que permitem sua formulação, apoios (B) que a tornam aceitáveis. As garantias possuem qualificadores modais $(\mathrm{Q})$ que emprestam força às conclusões - termos como certamente, presumivelmente, provavelmente, necessariamente, quase nunca 
-, além de circunstâncias excepcionais que, em casos específicos, podem ser refutadas (R). Quando a conclusão não apresenta ganho significativo de informação com relação à garantia, o argumento é considerado analítico. Neles, a conclusão é resultado óbvio dos dados e da garantia, como se apenas o embaralhamento das premissas fosse suficiente para se chegar à conclusão. Toulmin afirma que esse tipo de argumento é raro na prática cotidiana e os distingue de argumentos substanciais. Nestes, o argumento nunca é tautológico e as informações que permitem passar dos dados à conclusão são relevantes e substanciais (SCARPA; TRIVELATO, 2011, p.4).

Contudo, quando o professor atua em sala de aula com vistas a promoção da AC, recorrer ao Padrão de Toulmin é uma ação positiva, uma vez que ela consegue oferecer ao professor sugestões sobre como encaminhar, de maneira coerente e frutífera, as ações em sala de aula, na busca concreta construção do conhecimento científico nos alunos. Sasseron e Carvalho (2011) ao apresentarem os resultados de uma de suas pesquisas, enaltecem e discutem este apontamento.

A importância destas colocações, em nossa visão, reside em que, estudando o modo como os argumentos se constroem em sala de aula e percebendo o ciclo por meio do qual um das quais seja possível considerar de que maneira uma discussão pode ser desencadeada e encaminhada em sala de aula pelo professor. Não se trata somente de levá-lo a ter consciência da necessidade da argumentação como fator que leve os alunos a uma construção de conhecimentos que Ihes tenha mais significado; trata-se, também, de permitir ao professor que reconheça a necessidade de passos subsequentes durante as discussões e, assim, trabalhe para estimular o aparecimento dos mesmos em cada momento da aula (SASSERON; CARVALHO, 2011, p.112).

Enfim, afirmamos que o ensino de ciências tem urgência em ser promovido em sala de aula recorrendo a práticas argumentativas e, esta constatação se se deve ao fato de acreditarmos que é pelo argumento que o ensino adquire significado. Tal apontamento está em consonância com o pensamento de Kuhn (1993), quando disserta que:

É no argumento que nós podemos encontrar a maneira mais significativa na qual o pensamento e o raciocínio figuram na vida de pessoas comuns. Pensamento como argumento está implicado em todas as crenças que as pessoas têm, nos julgamentos que elas fazem e nas conclusões que elas tiram (KUHN, 1993, p.322). 
Argumentar é, portanto, uma ação que está para além de um simples ato classificado como simplório e banal, ele se faz essencial para o processo de formação cidadã bem como é um elemento intrínseco ao processo de construção da alfabetização científica. Corrobora com esta afirmação da supremacia e amplitude da argumentação no processo de ensino nas aulas de ciências, Motokane (2015) ao afirmar:

O desenvolvimento de habilidades argumentativas também promove a exteriorização da aprendizagem de um conteúdo ensinado quando os argumentos têm a chance de ser produzidos com base em argumentos científicos aprendidos em aula. Ao apresentarem seus argumentos, os alunos podem expressar como utilizam um determinado conceito científico para justificar uma opinião. Dessa forma, temos um indicador claro da aprendizagem do aluno (MOTOKANE, 2015, p.128-129).

A necessidade de se promover ações cotidianas nas aulas de ciências versadas pela argumentação garante também uma proximidade entre a vivência escolar e o contexto científico, neste caso, se faz necessário que esta aproximação ocorra, e, para além desta estreita relação constatamos que a argumentação em sala de aula garante um ensino coeso e de aplicabilidade, uma vez que os raciocínios estabelecidos pelas pessoas são em sua essência de natureza argumentativa (KUHN, 1993).

\section{Metodologia}

Recorremos a metodologia qualitativa para o desenvolvimento deste artigo, que é parte integrante de uma pesquisa de Doutorado em EC. O instrumento de coleta de dados aplicado foi um questionário com questões abertas, tendo como facilitador a ferramenta denominada Survio. Os discentes, alunos do 9 ano dos Anos Finais do Ensino Fundamental e da 3a série do Ensino Médio foram conduzidos durante as aulas de Ciências e de Biologia, respectivamente, à sala de informática da Unidade Escolar onde encontraram nos computadores os referidos questionários "introduzidos" na referida ferramenta. De posse das respostas dadas a este questionário aberto, nos debruçamos sobre a análise das mesmas e, para tanto adotamos a categorização. Neste caso, André e Ludke (1986) descrevem o 
processo de categorização ao dizerem:

A categorização, por si mesma, não esgota a análise. É preciso que o pesquisador vá além, ultrapasse a mera descrição, buscando realmente acrescentar algo à discussão já existente sobre o assunto focalizado. Para isso ele terá que fazer um esforço de abstração, ultrapassando os dados, tentando estabelecer conexões e relações que possibilitem a proposição de novas explicações e interpretações (ANDRÉ; LUDKE, 1986, p.49).

Ao analisarmos as respostas dadas ao questionário chegamos a conclusão de que existiam proposições e afirmações que requeriam novas explicações e interpretações, deste modo, emergiram dos dados categorias distintas, cada qual com sua especificidade como aponta Galiazzi e Moraes (2005):

Cada categoria corresponde a um conjunto de unidades de análise que se organiza a partir de algum aspecto de semelhança que as aproxima. As categorias são construtos linguísticos, não tendo por isso limites precisos. Daí a importância de sua descrição cuidadosa, sempre no sentido de mostrar aos leitores e outros interlocutores as opções e interpretações assumidas pelo pesquisador (GALIAZZI; MORAES, 2005, p.116).

De posse da identificação das categorias de análise nos debruçamos nas discussões que pudessem as novas respostas, ao longo desta construção pudemos evidenciar que apesar de nos atermos a duas categorias as discussões foram frutíferas e, de fato construíram um pensar e uma resposta aquilo que identificamos na análise inicial.

\section{Resultados e discussão}

De modo bem específico nos ateremos a analisar e buscar respostas a algumas das questões que compunham um questionário aplicado a discentes do 9 o ano do Ensino Fundamental e da 3a série do Ensino médio, pelo simples fato de que estas questões serviram de elemento norteador para o desenvolvimento da composição deste artigo, ou seja, nos voltaremos as questões que se referem a presença da temática argumentação no ensino de ciências e/ou biologia no Currículo do Estado de São Paulo e, também com que frequência a 
temática esteve presente nas aulas de Ciências e Biologia independentemente se ela consta ou não no documento citado. Vale salientar que os participantes desta pesquisa são alunos de uma escola da rede estadual do Estado de São Paulo, localizada em uma região de periferia do município de Campinas. Os participantes em questão, em uma aula do docente/pesquisador foram conduzidos ao laboratório de informática onde encontraram os questionários disponibilizados na tela. De modo bem específico, apresentamos no quadro II as questões e as respostas obtidas as quais são nosso referencial de discussão.

Quadro 2 - Aspectos Relativos a formação sobre Argumentação no Ensino de Ciências e a existência deste aprendizado no cotidiano.

\begin{tabular}{|c|c|}
\hline \multicolumn{2}{|c|}{ Qual é o grau de importância da Argumentação } \\
\hline 9o ano & 3a série \\
\hline 40,4\% Importante; & 50,0\% Importante; \\
\hline $40,4 \%$ Mais ou menos importante; & $21,9 \%$ Mais ou menos importante; \\
\hline 14,0\% Muito Importante; & 18,8\% Muito Importante; \\
\hline 5,2 Nada importante & 9,3\% Nada importante \\
\hline \multicolumn{2}{|c|}{ Formação específica sobre Argumentação no Ensino de Ciências e Biologia } \\
\hline 9o ano & 3a série \\
\hline $68,40 \% \operatorname{Sim}$ & $71,90 \% \operatorname{Sim}$ \\
\hline $31,60 \%$ Não & $28,10 \%$ Não \\
\hline \multicolumn{2}{|c|}{$\begin{array}{l}\text { Ao longo de sua vida estudante, até o presente momento você identificou nos livros didáticos utilizados nas } \\
\text { aulas de Biologia e ou Ciências alguma orientação ou encaminhamento que possibilitou o desenvolvimento } \\
\text { da argumentação? }\end{array}$} \\
\hline 9o ano & 3a série \\
\hline $54,40 \%$ Algumas vezes & $53,10 \%$ Algumas vezes \\
\hline $36,80 \% \operatorname{Sim}$ & $25,0 \% \operatorname{Sim}$ \\
\hline 8,80\% Não & $21,90 \%$ Não \\
\hline \multicolumn{2}{|c|}{$\begin{array}{l}\text { Os Cadernos do aluno para as disciplinas de Biologia e Ciências trazem, situaçã } \\
\text { possibilitam o desenvolvimento da argumentação? }\end{array}$} \\
\hline 9o ano & 3a série \\
\hline $35,10 \%$ Algumas vezes & $46,90 \%$ Algumas vezes \\
\hline $47,40 \% \operatorname{Sim}$ & $31,30 \% \operatorname{Sim}$ \\
\hline $17,50 \%$ Não & $21,80 \%$ Não \\
\hline
\end{tabular}

Fonte: elaborado pelos autores a partir dos dados obtidos pelo Survio. 
Fica evidente que, na concepção dos discentes que responderam a este questionário a temática argumentação nas aulas de Ciências e/ou de Biologia não foi uma habilidade de construção constante, chama a atenção conforme apresentado no quadro 2: $63,2 \%$ dos participantes do 9o ano apontam que nos livros didáticos adotados pela escola a temática argumentação foi de presença relativamente escassa, por enfatizarem que poucas foram as orientações para o desenvolvimento da argumentação. Para com a 3ạ série do Ensino Médio os dados obtidos são ainda mais preocupantes, uma vez que, 75\% dos participantes responderam que a frequência de orientações nos livros didáticos adotados pela escola foi escassa, ou seja, em algumas vezes ou não houve.

De modo bem específico os cadernos dos alunos, material base das escolas da rede do Estado de São Paulo, segundo 52,6\% dos discentes do 9 ano e, 68,8\% dos discentes da 3a série não trazem ou ocorre em algumas ocasiões apenas, situações de aprendizagem que possibilitam o desenvolvimento da argumentação.

Retomando a indagação: Qual é a percepção dos discentes quanto a periodicidade e as ações promotoras do desenvolvimento da competência argumentativa? Vislumbramos a partir das respostas obtidas que, na concepção e no apontamento deste discentes a existência de práticas que promovam a construção da argumentação no ensino de ciências e de biologia não é algo constante e, de fato possibilitador de construção desta habilidade.

Em busca a respostas a esta indagação nos recorre que, consta no Currículo a indicação do desenvolvimento da habilidade de argumentar e da competência da argumentação, logo, de modo a ratificar esta informação analisamos os quadros de habilidades do ensino de ciências e de biologia em busca do explícito comando de desenvolvimento da ação de argumentar ou de ações que se refiram a esta ação. A existência destas habilidades segue descritas nos quadros 3 e 4 . 
Quadro 3 - Análise da habilidade de argumentar no Currículo das disciplinas de Ciências

\begin{tabular}{|c|c|c|}
\hline \multicolumn{3}{|c|}{ Ensino Fundamental - 60 ao 90 ano - Componente Curricular: Ciências } \\
\hline Ano do ciclo de ensino & Bimestre & Descrição da habilidade \\
\hline 60 ano & 20 & $\begin{array}{l}\text { Construir, apresentar e reconhecer argumentação plausível para a } \\
\text { defesa da preservação da biodiversidade }\end{array}$ \\
\hline 60 ano & 20 & $\begin{array}{l}\text { Confrontar interpretações diversas dadas ao fenômeno do surgimento } \\
\text { da vida no planeta, comparando diferentes pontos de vista, identificando } \\
\text { os pressupostos de cada interpretação e analisando a validade dos } \\
\text { argumentos utilizados }\end{array}$ \\
\hline 6ano & 20 & $\begin{array}{l}\text { Elaborar argumentos consistentes para debater e enfrentar situações- } \\
\text { problema relativas ao uso do álcool como combustível }\end{array}$ \\
\hline 60 ano & 3 우 & $\begin{array}{l}\text { Identificar e argumentar sobre as vantagens e desvantagens dos } \\
\text { principais métodos de coleta e de destinação de lixo, tendo como } \\
\text { parâmetro a preservação ambiental e a saúde coletiva }\end{array}$ \\
\hline 60 ano & 4 은 & $\begin{array}{l}\text { Reconhecer argumentos e propostas que expressem a visão de que } \\
\text { saúde é um bem pessoal que deve ser promovido por meio de diferentes } \\
\text { ações (individuais, coletivas e governamentais), com base em textos }\end{array}$ \\
\hline 70 ano & 20 & $\begin{array}{l}\text { Construir, apresentar e reconhecer argumentação plausível para a } \\
\text { defesa da preservação da biodiversidade }\end{array}$ \\
\hline 70 ano & 20 & $\begin{array}{l}\text { Confrontar interpretações diversas dadas ao fenômeno do surgimento } \\
\text { da vida no planeta, comparando diferentes pontos de vista, identificando } \\
\text { os pressupostos de cada interpretação e analisando a validade dos } \\
\text { argumentos utilizados }\end{array}$ \\
\hline $7 \stackrel{0}{\text { ano }}$ & 4 운 & $\begin{array}{l}\text { Reconhecer argumentos e propostas que expressem a visão de que } \\
\text { saúde é um bem pessoal que deve ser promovido por meio de diferentes } \\
\text { ações (individuais, coletivas e governamentais), com base em textos }\end{array}$ \\
\hline 9o ano & 3 우 & $\begin{array}{l}\text { Reconhecer o princípio de funcionamento dos filtros solares e a validade } \\
\text { de argumentos que defendem o seu uso }\end{array}$ \\
\hline 90 ano & 3 우 & $\begin{array}{l}\text { Reconhecer o princípio de funcionamento dos filtros solares e a validade } \\
\text { de argumentos que defendem o seu uso }\end{array}$ \\
\hline
\end{tabular}

Fonte: SÃO PAULO, 2012, p.38-68 - grifo nosso 
Vislumbramos que a exceção do $8^{\circ}$ ano, em todos os anos do Ensino Fundamental, Anos Finais, há a orientação curricular para ações múltiplas para com a habilidade argumentativa, sendo estas pautadas pelas ações de reconhecer, identificar, construir, elaborar e validar argumentos e/ou argumentações.

Ao que parece há segundo consta o Currículo das Ciências da Natureza uma relação e também o enfatizar da relação entre a escrita e a leitura, ou seja, estão em consonância as habilidades leitora e escritora com a habilidade argumentativa, como cita São Paulo (2012):

Relacionar informações, representadas em diferentes formas, e conhecimentos disponíveis em situações concretas, para construir argumentação consistente. A leitura, nesse caso, sintetiza a capacidade de escutar, supor, informar-se, relacionar, comparar etc. A escrita permite dominar os códigos que expressam a defesa ou a reconstrução de argumentos - com liberdade, mas observando regras e assumindo responsabilidades (SÃO PAULO, 2012, p.19).

De forma a enaltecer esta salutar e imprescindível relação entre as competências leitora e argumentativa recorremos a descrição de São Paulo (2012), que ratifica esta estreita relação que classificamos como essencial para o processo de ensino-aprendizagem.

Recorrer aos conhecimentos desenvolvidos na escola para elaborar propostas de intervenção solidária na realidade, respeitando os valores humanos e considerando a diversidade sociocultural. Ler, nesse caso, além de implicar o descrever e o compreender, bem como o argumentar a respeito de um fenômeno, requer a antecipação de uma intervenção sobre ele, com a tomada de decisões a partir de uma escala de valores. Escrever é formular um plano para essa intervenção, formular hipóteses sobre os meios mais eficientes para garantir resultados a partir da escala de valores adotada. É no contexto da realização de projetos escolares que os alunos aprendem a criticar, respeitar e propor projetos valiosos para toda a sociedade; por intermédio deles, aprendem a ler e a escrever as coisas do mundo atual, relacionando ações locais com a visão global, por meio de atuação solidária (SÃO PAULO, 2012, p.19-20).

Da mesma forma que analisamos o componente curricular de Ciências em busca de evidências da existência do comando de desenvolvimento da habilidade argumentativa, realizamos para as habilidades do ensino médio na disciplina de Biologia, se de fato há a existência dos mesmos comandos, esta constatação segue descrita no quadro 4. 
Quadro 4 - Análise da habilidade de argumentar no Currículo das disciplinas de Biologia

\begin{tabular}{|c|c|c|}
\hline \multicolumn{3}{|c|}{ Ensino Médio - 1a à 3ạ série - Componente Curricular: Biologia } \\
\hline Ano do ciclo de ensino & Bimestre & Descrição da habilidade \\
\hline 1a série & 1 은 & $\begin{array}{l}\text { Debater e argumentar sobre a transformação da visão de mundo } \\
\text { geocêntrica em heliocêntrica, relacionando-a às mudanças sociais da } \\
\text { época }\end{array}$ \\
\hline 1a série & 30 & $\begin{array}{l}\text { Apresentar conclusões baseadas em argumentos sobre o impacto } \\
\text { positivo das tecnologias na melhoria da qualidade da saúde das } \\
\text { populações (vacinas, medicamentos, exames diagnósticos, alimentos } \\
\text { enriquecidos etc.) }\end{array}$ \\
\hline 2a série & 10 & $\begin{array}{l}\text { Debater e argumentar sobre avaliações e hipóteses acerca do } \\
\text { aquecimento global e suas consequências ambientais e sociais }\end{array}$ \\
\hline 2a série & 30 & $\begin{array}{l}\text { Reconhecer e argumentar sobre problemas decorrentes da poluição } \\
\text { sonora para a saúde humana e possíveis formas de controlá-los }\end{array}$ \\
\hline 2a série & 40 & $\begin{array}{l}\text { Analisar os argumentos relativos aos riscos e benefícios da utilização } \\
\text { de produtos geneticamente modificados disponíveis no mercado }\end{array}$ \\
\hline 3a série & 30 & $\begin{array}{l}\text { Pesquisar e argumentar acerca do uso de energia nuclear no Brasil e } \\
\text { no mundo }\end{array}$ \\
\hline
\end{tabular}

Fonte: SÃO PAULO, 2012, p.76-95

Ao analisarmos os quadros 3 e 4 pudemos constatar que, a orientação para o desenvolvimento e/ou construção da habilidade argumentativa está presente tanto nos Anos Finais do Ensino Fundamental, quanto nas séries do Ensino Médio. É notório que em menor escola e/ou frequência do que esperávamos, mas ratificamos a presença da habilidade e/ou ações que conduzam ao processo de aprendizagem pautado no viés da argumentação.

Diante da constatação de que o Currículo Oficial do Estado de São Paulo está voltado para o desenvolvimento da habilidade argumentativa e que, enaltece esta presença com a relação para com a competência leitora, nos indagamos: Por qual motivo, as respostas dos participantes apontam que a habilidade argumentativa tanto nos cadernos quanto nos livros didáticos, não é uma ação constante no âmbito escolar? 
Apontamos como possíveis causas deste antagonismo dois fatores: A formação docente e a resistência ao Currículo Oficial do Estado de São Paulo e, neste caso, promoveremos uma discussão acerca destes dois aspectos de modo a compreender e justificar o antagonismo que constatamos.

\section{A formação docente para a argumentação}

O ato de ensinar ciências pelo viés da argumentação não é uma prática diária da ação docente. O processo, em si, demanda que o docente tenha a consciência e concepção de que ele é o protagonista na condução da construção desta habilidade. Corrobora com nossa afirmação Sá Ibraim e Justi (2017) que enaltecem a ação do docente frente ao processo de aprendizagem das premissas da argumentação.

Entretanto, ensinar ciências por argumentação exige tanto uma ressignificação nos objetivos do ensino quanto que o professor assuma seu papel como agente responsável pelo desenvolvimento da prática argumentativa em sala de aula. Nesse sentido, Zohar (2008) defende que para que o professor possa atender as demandas de um ensino por argumentação é preciso que ele vivencie (em sua formação inicial ou continuada) práticas argumentativas que favoreçam o desenvolvimento dos conhecimentos e habilidades que auxiliem seu trabalho futuro com argumentação em suas classes de Ciências (SÁ IBRAIM; JUSTI, 2017, p.996).

A esta afirmação e ratificação da não frequência e aptidão docente para com o processo e prática de aprendizagem da argumentação no ensino de ciências atribuímos a formação, ou melhor dizendo a falta de formação e a resistência ao mudar de ideologia os motivos pelos quais os docentes não realizam diuturnamente ações para o desenvolvimento da habilidade argumentativa. Neste sentido, enaltecemos à luz de Sá Ibraim e Justi (2017) que existem pesquisas no âmbito da formação inicial e da formação continuada voltadas para este propósito e, as especificidades destes estudos são apresentadas em sua pesquisa, quando afirmam:

No que diz respeito à formação em argumentação, pesquisadores que têm realizado investigações no âmbito da formação continuada (SIMON; ERDURAN; OSBORNE, 2006) sinalizam que os professores apresentam resistências ao ensino de ciências pautado em argumentação devido ao tempo de aula necessário para que isto seja feito; e às dificuldades em romper com sua prática de ensino ou modificá-la. Por exemplo, Simon, Erduran e Osborne (2006) apontam que apenas os professores que demonstraram boas práticas para o

Periódico Horizontes - USF - Itatiba, SP - Brasil - e020016 
ensino de argumentação (por exemplo, encorajar os alunos a falar e a ouvir) no início do processo de formação analisado aperfeiçoaram-nas a partir do engajamento em tal processo de formação. Por outro lado, no âmbito da formação inicial, os licenciandos estão construindo suas identidades enquanto professores da educação básica e têm a oportunidade de ter acesso às discussões mais recentes sobre os objetivos educacionais e estratégias de ensino. Por isso, esses sujeitos tendem a apresentar menos resistência frente a novas perspectivas de ensino do que os professores que estão em exercício há muitos anos e que não participam de programas de formação continuada (SÁ IBRAIM; JUSTI, 2017, p.996-997).

A formação de docentes para as práticas da argumentação tem sido objeto e foco de pesquisas e, neste caso a pesquisa de Sá Ibraim e Justi (2017) enfatiza que o processo de formação inicial de docentes para a argumentação é possível desde que seja pautado por especificidades, sendo elas:

\begin{abstract}
Em relação aos aspectos metodológicos que fundamentaram o ensino explícito de argumentação, apontamos que o fato de as licenciandas terem vivenciado situações argumentativas influenciou o desenvolvimento de seus conhecimentos relativos à argumentação. Isto porque elas tiveram oportunidades de: (i) observar e discutir as ações da professora formadora enquanto mediadora de situações argumentativas; (ii) mobilizar seus conhecimentos de argumentação em situações simuladas de ensino; (iii) trabalhar com materiais favoráveis à prática argumentativa; e (iv) discutir sobre os elementos referentes à argumentação mobilizados nas situações vivenciadas (SÁ IBRAIM; JUSTI, 2017, p.1010).
\end{abstract}

Em suma, é preciso enfatizar que a formação inicial de professores para com a argumentação é uma ação que deve ser por um ensino explícito e que, acima de tudo a formação dos docentes deve ser mediada por vivências argumentativas e práticas pedagógicas favoráveis que enaltecem sua função de agente protagonista da condução desta habilidade.

Quando abordamos a problemática da formação docente como um elemento que pode ser o viés da resistência dos atuais docentes da rede Estadual de Ensino às práticas da argumentação no EC e de Biologia. A pesquisa de Sá Ibraim e Justi (2017) revela dados que dialogam ao serem realizadas práticas de formação específicas para com a argumentação científica, ou seja, tendo eles vivenciado práticas desta natureza, houve um desenvolvimento desta habilidade. Diante deste fato, cabe a problematização: Será que a formação acadêmica tem sido condizente para com a formação de um docente que instiga e possibilita a construção 
da argumentação em seus alunos? Com base nos dados da pesquisa de Sá Ibraim e Justi (2017), é possível constatar que processo de formação é de fato oposto ao tradicionalismo e, deste modo, podemos justificar a resistência do graduando e, futuramente do docente para com o desenvolvimento de práticas que promovam a construção da argumentação. Diante do exposto, podemos nos indagar: Mas por que há resistência de graduando às práticas argumentativas ao longo dos cursos de graduação? Para esta indagação, Santos Abib, Murillo e Lourenço (2016) discutem um possível motivo que justifique esta resistência ao dizerem:

Tais problemas decorrem, em sua maioria, do fato de cursos de formação inicial de professores se pautarem no modelo da racionalidade técnica para formarem futuros docentes. Este modelo de formação acaba por influenciar diretamente o contexto de sala de aula, já que geralmente forma professores que pouco refletem de modo sistemático sobre sua prática, pouco interagem e discutem com seus colegas sobre o trabalho docente e, sobretudo, pouco utilizam de aspectos teóricos para compreender e/ou melhorar sua prática. Esta situação se agrava quando se trabalha com professores das áreas de ciências exatas, pois, em muitos casos, a ciência acaba por ser tratada numa conotação simplista, a qual desconsidera a dúvida, o desenvolvimento, a argumentação e o diálogo na construção do conhecimento (SANTOS ABIB; MURILLO; LOURENÇO, 2016, p.296).

Diante do exposto, é preciso se ater aos meios para ressignificar esta situação, de modo que, os docentes possam ampliar a sua visão e a sua postura frente a aquisição do conhecimento específico de formação para a argumentação. Santos Abib, Murillo e Lourenço (2016) enfatizam em seu trabalho uma estratégia para que esta resistência possa ser erradicada do processo de formação docente.

Como resultado, os pesquisadores apontam a necessidade de ampliar espaços de reflexão para os professores, inclusive sobre as experiências vividas por eles e que tanto influenciam o seu fazer em sala de aula: É oportunizando momentos de intensa reflexão, dando voz ao professor, resgatando suas memórias, abrindo espaço para que o docente passe por um processo de "catarse", no qual se reconheça como profissional, descobrindo os motivos pelo qual apresenta determinadas atitudes, que se pode acreditar numa mudança de postura pedagógica. Não basta, simplesmente, oferecer a inovação ao professor, apresentando-Ihe uma receita, através da qual se vai conseguir uma aprendizagem efetiva. Por mais virtuosa que possa ser, atividade nenhuma se impõe por si só. Ela só ganha significado mediante a maneira do professor incorporá-la à sua prática cotidiana (MONTEIRO; TEIXEIRA, 2004, p.23). 
É extremamente importante destacar que, ainda no âmbito da formação inicial docente há um problema maior como aponta Sá Ibraim e Justi, 2017, p.1012 “há uma dicotomia entre os Parâmetros Curriculares Nacionais (BRASIL, 2002), documento que norteia o ensino básico, e o que é desenvolvido nos cursos de formação de professores". Ou seja, há necessidade de mudanças nos Parâmetros Curriculares de modo a apontar singularidade entre a existência da competência argumentativa que os alunos devem construir ao longo do processo de ensino e aprendizagem escolar e os documentos que norteiam a formação inicial dos doentes nas disciplinas pedagógicas específicas dos cursos de Licenciatura de modo que, com isso, possam os professores serem detentores da habilidade de promover o desenvolvimento da competência argumentativa em seus alunos.

\section{A resistência ao Currículo Oficial do Estado de São Paulo}

Esta categoria de análise é em detrimento da constatação da existência de comandos e orientações para o desenvolvimento da habilidade argumentativa e, o antagonismo observado pelo fato de que, os discentes afirmam a um questionário que, é apenas em algumas ocasiões e/ou de fato não acontece este processo de aprendizagem. Deste modo, diante deste antagonismo cabe a indagação: Por qual(is) motivo(s) isto ocorre? A vivência de um dos pesquisadores que pertence à rede estadual de ensino e, as pesquisas neste sentido, nos conduzem a constatação de quem se trata de uma resistência ao referido Currículo. De modo a justificar através da vivência nesta rede de ensino, é comum a afirmação dos docentes de que o âmbito escolar desta rede requer que o professor lide com variáveis que estão para além das especificidades da disciplina que leciona.

Neste sentido podemos dizer que ao promover uma discussão sobre os fundamentos didático-epistemológicos e político-pedagógicos realizam duas afirmações que enaltecem a necessidade de que o docente esteja em processo de formação constante e, que há um certo descompasso entre o tipo de material elaborado e por quem foi elaborado e a realidade dos alunos desta rede de ensino, fato este que corrobora com a possível resistência dos docentes ao Currículo Oficial do Estado de São Paulo. 
Em torno desta discussão de que o Currículo é um material organizado e que há uma incoerência no sentido da imposição do material do docente, fato este que gera também resistência ao mesmo, Gimeno Sacristán (2000) cita como deveria ocorrer a introdução de um currículo a docentes de modo a garantir a aceitação plena do mesmo.

Para permitir uma participação ativa dos docentes, o currículo não poderia ser concebido como propostas que automaticamente podem ser transferidas para a prática sem modificações de suas potencialidades, mas como hipótese, como tentativas a serem ensaiadas pelos professores em suas classes (GIMENO SACRISTÁN, 2000, p.176).

A incoerência nos procedimentos de elaboração do Currículo, fato este considerado como contribuidor da resistência ao mesmo, é uma das conclusões do trabalho de Zanotello e Pires (2016)

\begin{abstract}
A natureza persuasiva e autoritária, sob a égide da cientificidade, foi evidenciada nos discursos veiculados nos documentos oficiais que compõem o currículo. Além do ideal formativo compartilhado por seus autores na posição de representantes do Estado, há um investimento financeiro elevado para a produção e distribuição dos cadernos para todos os alunos da rede, e este é mais um motivo pelo qual é de se esperar que o Estado estabeleça meios para que seu currículo seja adotado. Mas, este movimento encontra resistências nas leituras que os protagonistas dos processos de ensino e aprendizagem fazem a partir de suas posições, resultando nas transformações pelas quais passam as propostas curriculares conforme descritas por Gimeno Sacristán (ZANOTELLO; PIRES, 2016. p.61).
\end{abstract}

Um outro fator que corrobora com a resistência do docente ao Currículo está no fato de que há uma exigência que camufla a livre ação docente frente as suas práticas, como aponta Santos e Frenedozo (2017)

Trazendo essa ideia posta por Novaes (2009) para os Cadernos de aulas desse currículo, entende-se que esses cadernos, de forma camuflada, retiram do professor o direito de decisão sobre o seu plano de aula, porque pauta-se na centralização do poder para a formação básica dos alunos (SANTOS; FRENEDOZO, 2017, p.6).

Um outro aspecto que corrobora para com a negação ao Currículo está na política adota 
pelo Governo do Estado ao vincular o pagamento do bônus ao resultado do IDESP. Assim, quando a escola atinge a meta estipulada pelo IDESP para cada ciclo de ensino da escola, o professor e demais integrantes da escola recebem um bônus em dinheiro. Como esta política desagrada a muitos dos docentes da rede, a resistência ao currículo por ser ele um elemento construtor e medidor da ação de atingir o índice do Idesp, os professores resistem ao mesmo, como aponta Santos e Frenedozo (2017)

Frente ao que se expõe, entende-se que é pouco provável que o professor não siga esses planos de aulas. Inclusive pelo fato de que o que está contido nos Cadernos (conteúdos, habilidades e competências) é o que será cobrado pelo SARESP, conforme afirma o documento denominado Matrizes de Referência para a Avaliação SARESP (SANTOS; FRENEDOZO, 2017, p.6).

Enfim, de modo bem específico para com as disciplinas de Ciências e Biologia, vislumbramos que o currículo é em sua grande maioria composto por aspectos negativos para o ensino destes componentes curriculares, uma vez que está pautado em aulas que priorizam a memorização e o "adestrar" dos alunos para uma avaliação externa da rede, o denominado SARESP.

\section{Considerações finais}

Alguns aspectos pontuais puderam ser evidenciados com a elaboração deste artigo, sendo eles a ratificação de que a temática argumentação no EC é uma das habilidades a serem desenvolvidas nos discentes da rede do Estado de São Paulo. Este fato enaltece a preocupação da Secretaria do Estado da Educação e promover um ensino pautado por um viés que é antagônico ao ensino tradicional, em especial por agregar e relacionar a habilidade argumentativa a competência leitora.

Identificamos a presença de comandos para o desenvolvimento de habilidades voltadas as questões do argumento e da argumentação tanto no ensino de ciências, anos finais, com exceto no oitavo ano deste ciclo, encontramos também a presença de habilidades em todas as séries do ensino médio.

Ao analisarmos as respostas dos discentes de uma das escolas estaduais do Estado de São

Periódico Horizontes - USF - Itatiba, SP - Brasil - e020016 
Paulo observamos um antagonismo frente a esta evidente presença do desenvolvimento das habilidades argumentativas, no que diz respeito a afirmação de que a ação da construção da argumentação acontecia em apenas algumas ocasiões ou não acontecia.

Em busca a respostas que justificassem este antagonismo, chegamos a conclusão de que este fato estava atrelado a dois fatos que classificamos como categorias na construção desta resposta, sendo eles: A formação inicial docente e a resistência ao Currículo Oficial do Estado de São Paulo. Concluímos que, de fato, a formação inicial docente para com a argumentação requer mudanças metodológicas, bem como é preciso que os documentos que regem tanto a educação básica quanto a formação docente estejam em consonância, de modo a promover um ensino e uma aprendizagem de fato significativa. No que se refere a resistência ao currículo pudemos evidenciar que de fato ela acontece em detrimento a visão, leitura e incoerências na elaboração e no objetivo do mesmo, que não é aceito pelos docentes integrantes desta rede de ensino.

\section{Referências}

BRASIL. Ministério da Educação. Parâmetros curriculares nacionais. Brasília, 2002.

CASTRO, M. H. G. Carta da secretária. In: Proposta Curricular do Estado de São Paulo: Educação Física. São Paulo: SEE, 2008.

COSTA, A. Desenvolver a capacidade de argumentação dos estudantes: um objectivo pedagógico fundamental. Revista Iberoamericana de Educación, v.46, n.5, p.1-8, 2008.

GIMENO SACRISTÁN, J. O currículo: uma reflexão sobre a prática. 3. ed. Porto Alegre: Artmed, 2000.

KUHN, D. Science as argument: implications for teaching and learning scientific thinking, Science Education, v.77, n.3, p.319-337, 1993.

LÜDKE, M.; ANDRÉ, M. E. D. A. Pesquisa em educação: abordagens qualitativas. São Paulo: EPU, 1986.

MONTEIRO, M. A. A.; TEIXEIRA, O. P. B. Uma análise das interações dialógicas em aulas de ciências nas séries iniciais do ensino fundamental. Investigações em Ensino de Ciências, v.9, n.3, p.243-263. 2016.

MORAES, R.; GALIAZZI, M. C. Análise textual discursiva. Ijuí: Unijuí, 2005. 
MOTOKANE, M. T. Secuencias didácticas investigativas y argumentación en la enseñanza de la ecología. Ensaio Pesquisa em Educação em Ciências, Belo Horizonte, v.17, p. 115-138, 2015.

SÁ IBRAIM, S.; JUSTI, R. Influências de um ensino explícito de argumentação no desenvolvimento dos conhecimentos docentes de licenciandos em Química. Ciência \& Educação, Bauru, v.23, n.4, p.995-1015, 2017.

SANTOS ABIB, M. L. V.; MURILLO, F. J.; LOURENÇO, A. B. Aprendendo a ensinar e a argumentar: Saberes de Argumentação Docente na formação de futuros professores de química. Revista Brasileira de Pesquisa em Educação em Ciências, 2016, vol. 16, no 2, p. 295-316.

SANTOS, R.; FRENEDOZO, R. C. Uma análise crítica sobre o atual currículo oficial da rede de ensino da Secretaria da Educação do Estado de São Paulo. In: XI ENCONTRO NACIONAL DE PESQUISA EM EDUCAÇÃO EM CIÊNCIAS. Anais. Universidade Federal de Santa Catarina, Florianópolis, SC, 2017, p. 1-9.

SÃO PAULO. Secretaria da Educação. Currículo do Estado de São Paulo: Ciências da Natureza e suas tecnologias. São Paulo: SE, 2012.

SASSERON, L. H.; CARVALHO, A. M. P. Almejando a alfabetização científica no ensino fundamental: a proposição e a procura de indicadores do processo. Investigações em Ensino de Ciências, v.13, n.3, p.333-352. 2008.

SASSERON, L. H.; CARVALHO. A. M. P. Construindo argumentação na sala de aula: a presença do ciclo argumentativo, os indicadores de alfabetização científica e o padrão de Toulmin. Ciência \& Educação, Bauru, 2011, v.17, n.1, p.97-114. 2011.

SCARPA, D; TRIVELATO, S. L. F. Características linguísticas e argumentativas de artigos científicos que participaram da construção do paradigma do DNA como portador das informações hereditárias. In: ATAS DO VIII ENCONTRO NACIONAL DE PESQUISA EM EDUCAÇÃO EM CIÊNCIAS. Anais [...] Campinas, SP, Brasil.

SECRETARIA DO ESTADO DA EDUCAÇÃO, São Paulo. SARESP: documento de implantação. São Paulo: FDE, 1996.

SOUSA, S. Z.; ARCAS, P. H. Implicações da avaliação em larga escala no currículo: revelações de escolas estaduais de São Paulo. Educação: Teoria e Prática, v.20, n.35, p.181, 2010.

ZANOTELLO, M.; PIRES, M. O. C. Discursos sobre o currículo oficial do estado de São Paulo no contexto de um curso de formação continuada para professores de Física. Ciênc. educ., Bauru, v.22, n.1, p.43-63, mar. 2016. 
Recebido em outubro de 2019.

Aprovado em fevereiro de 2020. 